\title{
Transient adrenal insufficiency secondary to chronic opioid drug therapy
}

N Vanderpant ${ }^{1}$, V Bravis ${ }^{1,2}$

Department of Diabetes and Endocrinology, St Marys Hospital, Imperial College Healthcare NHS Trust, London Division of Diabetes, Endocrinology and Metabolism, Imperial College London

\section{Introduction}

Opioids are commonly used in clinical practice to treat both acute and chronic pain. Opioids have been previously reported to cause endocrinopathies, however most reported cases focus on hypogonadotrophic hypogonadism.[3]

Opioid induced adrenal insufficiency is likely an under recognised phenomenon. There have been cases of opioid use causing clinically significant secondary adrenal insufficiency however few which report primary adrenal insufficiency, as in the following case report.

\section{Case Report}

- A 54 year old female presented to hospital with severe back pain. On further questioning she also reported episodes of feeling light headed and associated fatigue.

- She had a past medical history of severe chronic back pain for which she was using high doses of opioid medications; Tramadol 100mg QDS, gabapentin $75 \mathrm{mg} \mathrm{BD}$ and oromorph $10 \mathrm{mg}$ PRN.

- On clinical examination she was noted to have hyperpigmentation of her lips and buccal membranes. She was hypotensive with a systolic blood pressure of $80 \mathrm{mmHg}$.

- She underwent investigations as an inpatient. A 9 am cortisol and a short synacthen test revealed a suboptimal cortisol rise associated with a raised ACTH level. (Table 1)

- A long synacthen test, also showed an insufficient peak cortisol of 796nmol/L. (Table 2)

- Imaging showed no pituitary or adrenal abnormalities.(Table 2)

- She was commenced on treatment with hydrocortisone $10 \mathrm{mg}, 5 \mathrm{mg}, 5 \mathrm{mg}$ which improved her symptoms and her dizzy episodes resolved.

- 5 months following presentation a repeat short synacthen test confirmed ongoing hypocortisolaemia. (Table 1)

- 9 months following initial presentation, the patient was referred to the pain team and commenced regular physiotherapy and acupuncture. She was commenced on pregabalin and over the next few months her opioid medications were weaned down and stopped.

- 20 months following initial presentation, full recovery of the adrenal axis was confirmed (Table 1) and hydrocortisone treatment was ceased. She has remained well, off glucocorticoid replacement since then.

\section{References}

[1] Abs R, Verhelst J, Maeyaert J, Van Buyten JP, Opsomer F, Adriaensen H, Verlooy J, Van Havenbergh T, Smet M \& Van Acker K. 2000. Endocrine consequences of long-term intrathecal administration of opioids. Journal of Clinical Endocrinology and Metabolism 85 2215-2222. 10.1210/jcem.85.6.6615

[2] Policola C, Stokes V, Karavitaki N \& Grossman A. 2014. Adrenal insufficiency in acute oral opiate therapy. Endocrinology, Diabetes \& Metabolism Case Reports 2014130071 10.1530/EDM-13-071

[3] Singh N, Snyder RW \& Krishnamurthy M. 2014. An under-recognized and under-reported cause of adrenal insufficiency. International Journal of Case Reports in Medicine 2014 (Article ID 524908) 10.5171/2014.524907

[4] Allolio B, Deuss U, Kaulen D, Leonhardt U, Kallabis D, Hamel E, et al. FK 33-824, a met-enkephalin analog blocks corticotropin-releasing hormone-induced adrenocorticotropin secretion in normal subjects but not in patients with Cushing's disease. J Clin Endocrinol Metab. 1986;63:1427-1431.

[5] Lee C, Ludwig S, Duerksen DR. Low-serum cortisol associated with opioid use: case report and review of the literature. Endocrinologist. 2002;12:5-8.

[6] Taylor T, Dluhy RG, Williams GH. $\beta$-endorphin suppresses adrenocorticotropin and cortisol levels in norma human subjects. J Clin Endocrinol Metab. 1983;57:592-596
Investigations

Table 1 Serial short synacthen tests

at 0,5 and 20 months after initial presentation

\begin{tabular}{|c|c|c|c|c|}
\hline $\begin{array}{l}\text { Time after } \\
\text { presentation } \\
\text { (months) }\end{array}$ & $\begin{array}{l}\text { Cortisol } \\
\text { (nmol/L) time } 0 \\
\text { (mins) }\end{array}$ & $\begin{array}{l}\text { Cortisol } \\
\text { (nmol/L) time } \\
30 \text { (mins) }\end{array}$ & $\begin{array}{l}\text { Cortisol } \\
\text { (nmol/L) time } \\
60 \text { (mins) }\end{array}$ & ACTH (ng/L) \\
\hline 0 & 38 & 419 & 632 & 103 \\
\hline 5 & 43 & 331 & 433 & (not tested) \\
\hline 20 & 362 & 469 & 566 & 25 \\
\hline
\end{tabular}

Table 2 Biochemical and imaging investigations at presentation

$\begin{array}{ll}\text { Investigation } & \text { Result } \\ \text { Adrenal antibodies } & \text { negative } \\ \text { Long synacthen test (peak cortisol) } & 796 \mathrm{nmol} / \mathrm{L} \\ \text { Renin } & 1.2 \mathrm{pmol} / \mathrm{ml} / \mathrm{hr} \\ \text { Aldosterone } & <78 \mathrm{pmol} / \mathrm{L} \\ \text { MRI adrenals } & \text { Normal appearance, no mass or } \\ & \text { altered signal } \\ \text { MRI pituitary } & \text { Normal appearance } \\ \text { MRI whole spine } & \text { Degenerative changes L4/5, normal } \\ & \text { spinal cord }\end{array}$

\section{Discussion}

This unusual case demonstrates primary adrenal insufficiency as a result of chronic opioid use. As in several other cases reported, this dysfunction was fully reversible on cessation of the opioids. ${ }^{2,3}$

Prolonged use of opioids may indeed mimic adrenocortical failure. Opioids used on a daily basis have been reported to affect the hypothalamic-pituitary-adrenal (HPA) axis at multiple levels ${ }^{4,5}$ and opioid endocrinopathy has been documented as early as the 18th century. This phenomenon, is an under-recognised endocrinopathy with potentially life-threatening adverse effects and also blunts the cortisol response to corticotropin. 4,6

Given the widespread use of opioids, there should be more awareness amongst clinicians of these drug-induced endocrinopathies. Treatment strategies to prevent adrenal insufficiency in the context of opioid use, could include supervised weaning of opioid drugs and use of alternative modalities and interventional pain techniques. Also, risk and benefits of opioid drug use should be explained to patients at the onset of therapy. Further research to characterise the incidence and types of these endocrinopathies would be beneficial. 